\title{
Enabling personalized medicine in Europe by the European Commission's funding activities
}

\begin{abstract}
Personalized medicine (PM) is an emerging approach to prevention, diagnosis, treatment and care. It helps to address the challenge of the aging of the population, an increase in chronic disease and increasing healthcare costs. The EU is developing policies to move toward PM. This is underpinned by a sustained and significant investment starting in 2010. So far, a total of $€ 3.2$ billion has been invested in PM research across the medical innovation cycle 'from bench to bedside'. This investment has come from the research framework programs FP7 and Horizon 2020. About a third of the total investment has been made in the context of the Innovative Medicines Initiative, the largest public-private partnership in life sciences globally.
\end{abstract}

First draft submitted: 10 January 2017; Accepted for publication: 4 April 2017; Published online: 23 June 2017

Keywords: EU funding $\bullet$ personalized medicine $\bullet$ policy development

The aging of the population and chronic disease are prominent challenges, which not only affect societies in richer countries but are rising across the world. Despite the tremendous medical progress made in the last decades, much remains to be done and for many diseases we do not have effective interventions. In many cases, interventions are not targeted to the individual. They may work in some individuals but not in others, who nevertheless may suffer all the associated negative consequences. Side effects of medicines represent one of the leading causes for hospital admissions, with studies showing that 2 to $>6 \%$ of hospital admissions are for this reason [1-5]. In the context of economic strain, the sustainability of healthcare systems is challenged by increasing healthcare costs.

The medical approach of personalized medicine (PM) will help address these challenges. The accumulated and further rapidly growing knowledge about the genetic basis of health and disease, combined with a careful characterization of individuals (e.g., molecular profiling, medical imaging and lifestyle data) is used for targeted approaches to prevent, diagnose and treat disease. This is also the definition of PM in Europe, as noted in the Conclusions of the Council of the EU at its meeting of 7 December 2015.

Other terms, such as 'precision medicine', 'stratified medicine', 'individualized medicine', 'genomic medicine', 'pharmacogenomics' and 'P4 medicine' (for personalized, predictive, preventive and participatory) are also used. A systematic review on definitions of PM has been published [6]. Whichever term is used, it is important to emphasize that PM is not only about medicines (pharmaceuticals/medicinal products). Rather, putting the person at the center - better understanding the genetics, the detailed biological mechanisms and interactions with the environment, as understood in a broad sense - will profoundly impact how prevention and medicine are practiced and how biomedical research is carried out.
Elmar Nimmesgern ${ }^{*, 1}$, Irene Norstedt ${ }^{1} \&$ Ruxandra Draghia-Akli'

${ }^{1}$ Directorate-General for Research \& Innovation, European Commission, B-1049 Brussels, Belgium *Author for correspondence: elmar.nimmesgern@ec.europa.eu

Future
Medicine
part of 
In this paper we discuss the EU policy context for the development of PM in Europe and describe the funding that has been made available in support of PM.

The European Commission has been a driver for the development of PM approaches so that they can be readily implemented in healthcare practice. Its efforts started already in 2010 with a series of workshops exploring different research areas that can make a contribution to developing PM. The results from the workshops were brought together in a 2011 conference entitled European Perspectives in Personalized Medicine [7].

Challenges identified at this conference led to a large effort of funding PM research at EU level (detailed below) and this effort, built on significant earlier investments in '-omics' research, is ongoing.

In parallel to the research activities, reflections on PM policy development have also taken place at EU level. The first major policy document was the report 'Use of '-omics' technologies in the development of personalized medicine' [8], placing the challenges for advancing PM in the context of the medical innovation cycle 'from bench to bedside' (Figure 1).

Changes of the framework for biomedical research and innovation and the way healthcare is practiced are furthermore based on the evidence resulting from funded programs. The report concluded that PM offers new opportunities for treatment of patients in the EU, by better targeting treatments, avoiding medical errors and reducing adverse reactions to medicines.

Since 2011, a number of EU laws have been adopted that will support the development of PM. They include:
- the clinical trials regulation [9], which will facilitate the conduct of clinical trials in the EU;

- the general data protection regulation [10], which makes the legal framework in this area fit for the digital age;

- the in vitro diagnostics and medical device legislation [11], which aims at adapting the EU legislation to the technological and scientific progress in this sector.

Under the Luxembourg presidency of the EU (July-December 2015), the European health ministers have adopted Council conclusions on PM [12]. They note that PM is becoming a reality in research, particularly following the support through the EU research funding program Seventh Framework Program for research, technological development and demonstration activities [13] and that funding research for PM continues in Horizon 2020 [14], including actions carried out under the Innovative Medicines Initiative (IMI) [15].

The discussions on PM at EU level echo activities at the level of the EU member states, such as those carried out by the UK Academy of Medical Sciences [16], the German Academy of Sciences Leopoldina and the German Personalized Medicine Action Plan [17,18] or the Genomic Medicine France 2025 plan [19].

To develop a joint European research and innovation policy for PM, the European Commission has launched the 'Personalized Medicine 2020 and beyond - Preparing Europe for leading the global

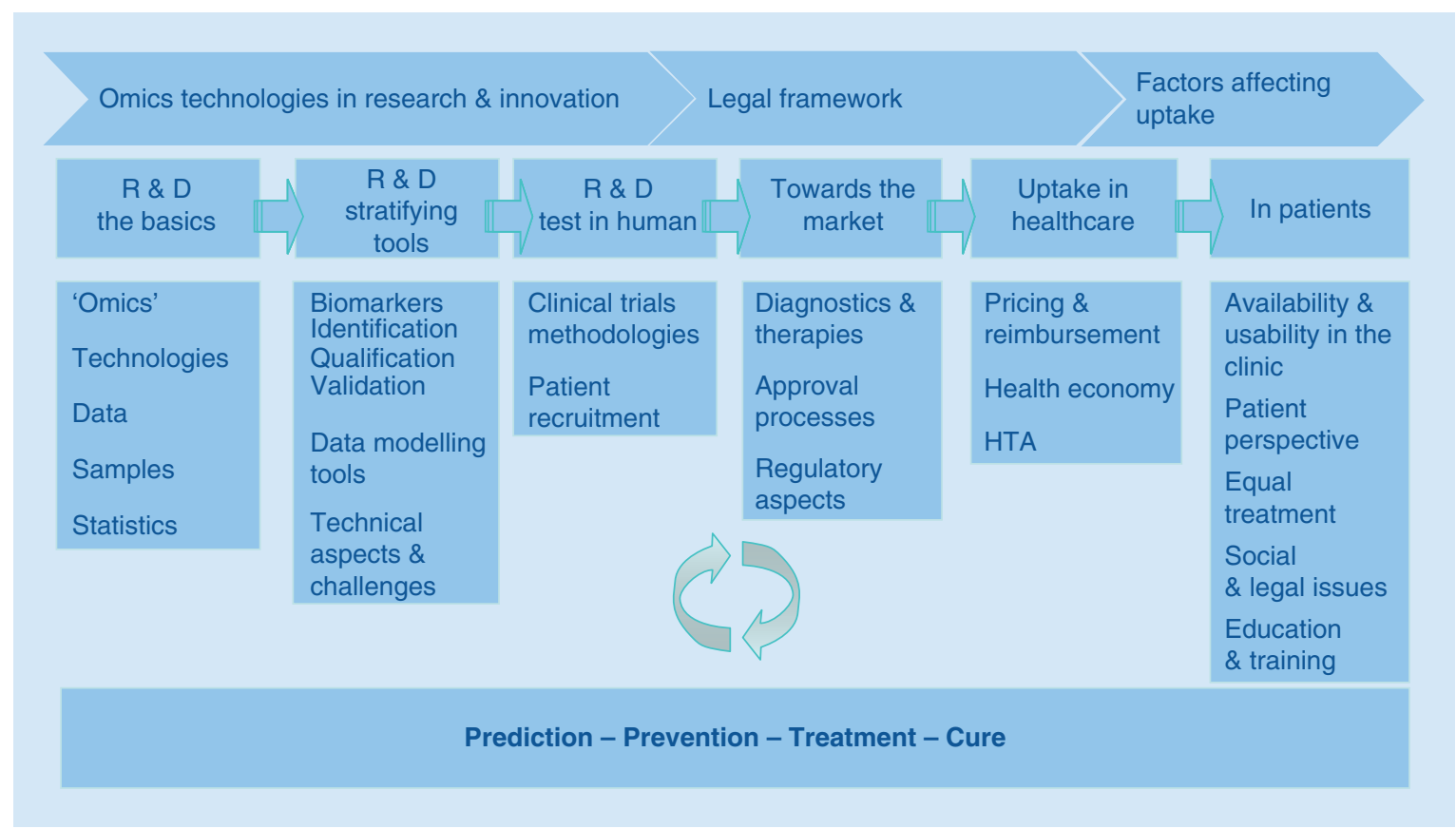

Figure 1. Challenges for personalized medicine across the medical innovation cycle.

HTA: Health technology assessment. 
way (PerMed)' project [20]. Based on the involvement of stakeholders and policy makers, PerMed has prepared a strategic research and innovation agenda [21] identifying five challenges to advance PM:

- developing awareness and empowerment;

- entegrating big data and ICT solutions;

- translating basic to clinical research and beyond;

- bringing innovation to the market;

- shaping sustainable healthcare.

To put the PerMed agenda into practice, DG Research and Innovation of the European Commission [22] has led discussions with research and health policy makers from across Europe, leading in June 2016 to a high level European PM conference organized in Brussels [23]. The conference has informed the work to translate the PerMed challenges into an action list, which can be implemented by research funders and health and research policy makers across Europe and the world. The discussions have also crystallized into the creation in November 2016 of an International Consortium for Personalized Medicine, or IC PerMed. The creation of IC PerMed and the contribution of the EU programs to its implementation have been described [24]. IC PerMed will work to:

- $\quad$ establish Europe as a global leader in PM research;

- support the PM science base through a coordinated approach to research;

- provide evidence to demonstrate the benefit of PM to citizens and healthcare systems;

- $\quad$ pave the way for PM approaches for citizens.

\section{EU funding for personalized medicine Overall context for EU research funding}

According to the European treaties, the EU has competence in coordinating research in Europe and in implementing a Europe-wide program for supporting research and innovation, as illustrated by the 7th EU research framework program (FP7, 2007-2013) [13,25], followed by Horizon 2020 started in 2014 and running until 2020 [14,26]. The EU research framework programs are among the largest integrated research funding programs in the world. In the area of health research they represent only approximately $10 \%$ of the funds made available at Member State level; nevertheless, they represent approximately $95 \%$ of collaborative, high impact research [27].
The programs include the well-known Marie Skłodowska-Curie research fellowships program, the European Research Council, support for industrial leadership, financial instruments, etc. Health research is fostered in many different parts of the programs, but both the previous and current program have specific parts addressing biomedical research. In FP7, this was the Health Theme of the cooperation program, whereas in Horizon 2020 it is the Societal Challenge 1 'Health, demographic change and wellbeing'.

\section{Specific budget allocation for health research in FP7 \& Horizon 2020}

The distribution of the overall budget of FP7 and Horizon 2020 is as shown in Table 1.

Within the Cooperation program, in FP7 a total of $€ 6.1$ billion has been allocated to the Health Theme. Among the Societal Challenges, $€ 7.4$ billion was allocated to Societal Challenge 1 'health, demographic change and wellbeing'.

\section{Innovative Medicines Initiative}

In 2008 the IMI was created. IMI is a public-private partnership between the EU, represented by the European Commission and the European researchbased pharmaceutical industry, as represented by its umbrella organization European Federation of Pharmaceutical Industries and Associations (EFPIA) with the goal to support pharmaceutical research and innovation in Europe.

IMI supports collaborative projects where EFPIA companies invest own resources in kind and the IMI joint undertaking funds through allocations received from the European Commission (part of the FPs) the other partners in the projects, such as academic researchers, research institutes, small and mediumsized enterprises, patient organizations, regulators and other stakeholders, as appropriate.

Building on the success of IMI, it was decided to continue the partnership under Horizon 2020. Compared with IMI, IMI2 is open to other stakeholders beyond the pharmaceutical industry to become involved as associated partners and several such partners are already contributing to IMI2. Also the strategic research agenda of IMI2 has been expanded compared with IMI and is more explicitly focused on unmet medical need. It is titled 'The right prevention and treatment for the right patient at the right time' [28] and is based on the 'WHO priority medicine report for Europe and the World', updated in 2013 [29]. The projects address from antimicrobial resistance and Ebola, to how to better use data to improve the drug development process. Overall IMI2 is well-placed for speeding up the development and uptake of innovative 
Table 1. Overall structure of EU research programs FP7 and Horizon 2020.

FP7 (2007-2013)

\begin{tabular}{|c|c|c|c|}
\hline Main program sections & Budget (billion $€$ ) & Main program sections & Budget (billion $€$ ) \\
\hline Cooperation & 32.4 & Societal challenges & 29.7 \\
\hline $\begin{array}{l}\text { Of which for the 'Health } \\
\text { Theme', incl. IMI }\end{array}$ & 6.1 & $\begin{array}{l}\text { Of which for the 'Health, } \\
\text { demographic change and } \\
\text { wellbeing challenge', incl. } \\
\text { IMI2 }\end{array}$ & 7.4 \\
\hline $\begin{array}{l}\text { Funding for PM research } \\
\text { in the 'Health Theme', } \\
\text { including IMI }\end{array}$ & 1.7 & $\begin{array}{l}\text { Funding for PM research in } \\
\text { the 'Health, demographic } \\
\text { change and wellbeing } \\
\text { challenge, incl. IMI2 } \\
\text { projects so far }\end{array}$ & 0.92 \\
\hline Ideas & 7.5 & Excellent Science & 24.4 \\
\hline People & 4.8 & Industrial Leadership & 17 \\
\hline Capacities & 4.1 & $\begin{array}{l}\text { European Institute of } \\
\text { Technology }\end{array}$ & 2.7 \\
\hline Joint Research Centre & 1.7 & Other (incl. JRC) & 3.2 \\
\hline Total & $50.5^{\dagger}$ & Total & $77^{\dagger}$ \\
\hline
\end{tabular}

medicines, particularly in areas where there is a high unmet medical need. A particular focus of IMI has always been on PM approaches, which has been reinforced under IMI2. The total investment in IMI is more than $€ 5.2$ billion for the period from 2008 through 2024. Detailed information on IMI as such and its support to PM agenda is provided on the IMI website [15].

\section{Analysis of funding for PM}

The complete set of projects from FP7 is known. In contrast, Horizon 2020 runs until 2020, and the projects selected until now are from the calls 2014-2016. Topics are still open or proposals are in the process of being evaluated for the funding that will be made available from the 2017 budget. Furthermore, calls for proposals are being prepared for the period 2018-2020. Thus, now we can only give a snapshot of the investment in PM research and innovation in Horizon 2020.

Support for PM research in FP7 \& Horizon 2020 Under the FP7 Health Theme, 1008 projects have been funded, for a total EU contribution of $€ 4.8$ billion. The remainder of the budget allocation to the FP7 Health Theme has been invested on activities such as IMI, and other partnerships.

Out of the FP7 Health Theme-funded projects, a total of 209 address PM and the EU contribution for the projects is $€ 1334$ million. The 209 projects represent 2756 participations of various research entities, of which $512(19.9 \%)$ are from small- and mediumsized enterprises (SMEs). With a budget allocation among the PM projects to SMEs of some $€ 251$ million, at $18.8 \%$ the share of the overall investment going to SMEs is slightly higher than the overall share of FP7 funding going to this type of enterprize. Thus it can be concluded that the PM projects contributed to achieving the FP7 goal of investing at least $15 \%$ of EU funding from the Health Theme into SMEs.

Looking at the timing of the launch of projects under FP7 one can see a rise in the share of investment in projects addressing PM from 2007, the first year of the program to 2012, the fifth year, and staying at a high level for the remaining 2 years, as shown in Figure 2.

For Horizon 2020 so far 293 projects have been selected under Societal Challenge 1 'health, demographic change and wellbeing', representing an EU investment of some $€ 1.6$ billion. Out of those projects, 163, that is, more than half, address PM and more than $€ 870$ million have been invested in the projects so far. The projects can be found in all areas under Societal Challenge 1 . The relatively largest number of projects is being supported in the area 'treating and managing disease', with 61 projects being funded so far. 22 projects are being supported under the subarea 'understanding disease'.

The PM projects which have been selected under FP7 and Horizon 2020 address a broad range of activities, from large-scale data gathering and '-omics', 


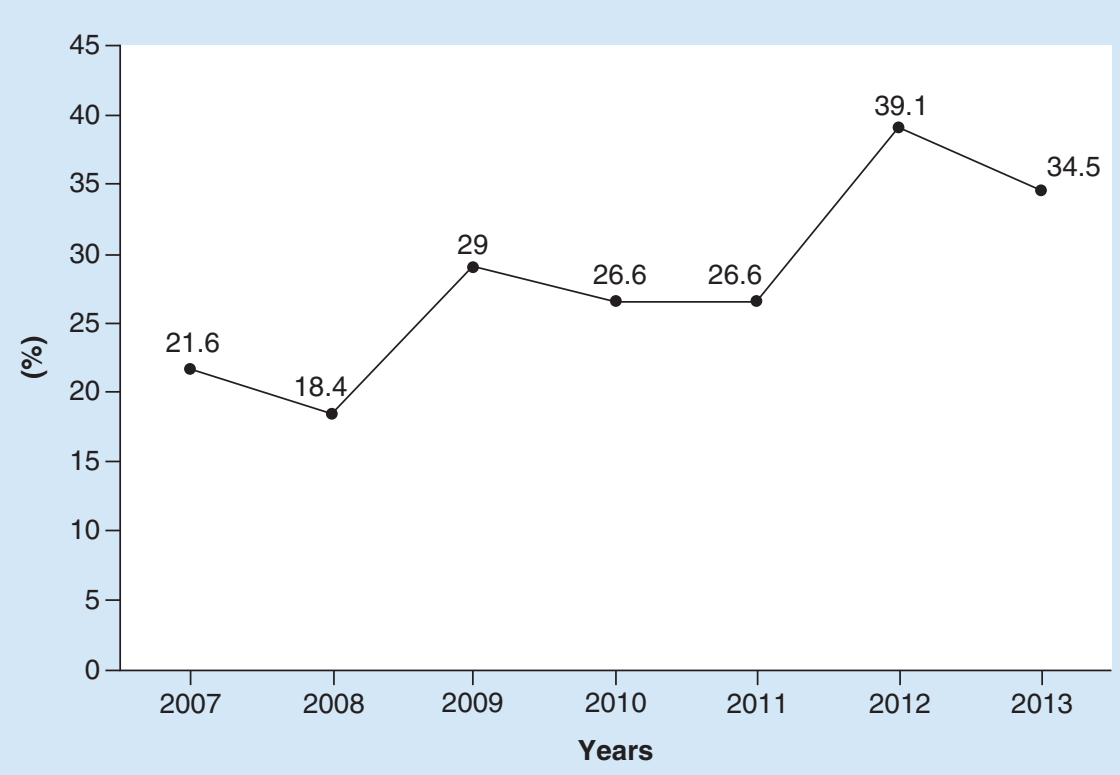

Figure 2. Share of investment in personalized medicine projects during FP7 over time.

technology development, diagnostics, biomarkers, clinical trial methodologies, preclinical and clinical research, '-omics' for health promotion and disease prevention to piloting PM in healthcare. A particular mention should be made of the investment in rare disease research. That investment, which is made in the context of the international rare disease research consortium IRDiRC [30] is not a topic for this paper as such. However, many of the rare disease projects supported by EU research funding are also PM projects and provide information that is relevant for advancing PM more generally. This applies, for example, to the projects on clinical trial methodologies for small populations, which are a necessity in rare disease research because of the low number of patients with a given condition. In PM, depending on the condition and the level of stratification, one also arrives at small populations.

The following projects are briefly discussed to show the breadth of PM research that has been supported through EU health research funding.

New diagnostic tests that help stratify patients have been a focus of EU funding in PM. An example is the sustained effort on developing a 70 -gene signature for stratifying breast cancer patients, which has been proven to save women from receiving unnecessary chemotherapy while ensuring the same outcome. These tests were developed in the TRANSBIG Network of Excellence, which had been funded under the 6th FP [31].

The BLUEPRINT 'A BLUEPRINT of Haematopoietic Epigenomes' project [32] was one of the High
Impact Projects that were launched under FP7 to tackle major health research challenges in a coordinated fashion. The project brings together 42 partners who received almost $€ 30$ million of EU support over 5 years (2011-2016). BLUEPRINT was a cornerstone of the International Human Epigenome Consortium (IHEC), a worldwide initiative coordinating research on the human epigenome. The project studied the epigenetic mechanisms involved in hematopoiesis and fully delivered, exceeding expectations. The consortium produced an immense amount of epigenetic data, adhering to strict quality and ethical standards. The project partners contributed to the development of new technologies as well as standard operation procedures and data sharing mechanisms that serve as common worldwide standards in epigenomics. Among many important discoveries, the BLUEPRINT researchers elegantly demonstrated the feasibility of epigenetic analysis for clinical diagnostics [33-36]. The impressive body of knowledge produced by this project is exemplified, for example, by the major coordinated set of publications recently released. BLUEPRINT researchers contributed to 26 out of a total of 41 publications authored by International Human Epigenome Consortium member projects. All these achievements lay the grounds for the wider incorporation of epigenetic data into the development of PM approaches.

Another example is the GAPVAC project 'The Glioma Actively Personalized Vaccine Consortium', with $€ 6$ million invested from the FP7 program for 2012-2017 [37]. The project aims to develop a highly innovative personalized immunotherapy to improve 
treatment of patients with glioblastoma. In a Phase I/II study glioblastoma patients receive a fully personalized peptide-based vaccine as a result of full-genome sequencing and complete peptidomics analysis of the patient's tumor. The latest developments in next-generation sequencing, proteomics, immunology, biomarker research and small-scale GMP peptide manufacturing are combined to a PM approach to cancer patients. Project goals include testing safety, feasibility and efficacy (biological and early clinical) of this novel personalized immunotherapy. GAPVAC project includes 13 participants from Denmark, Germany, Israel, The Netherlands, Spain, Switzerland and the UK.

The issue of clinical trials in small populations has been addressed by three FP7 projects focusing on rare disease but with obvious relevance for PM. ASTERIX, IDeAl and InSPiRe [38-40] (EU contributions of $€ 3$ million, $€ 2.96$ million and $€ 2.27$ million, respectively) work on the development of new or improved statistical design methodologies for clinical trials for small population groups. The projects provide input to regulatory science, as recognized by the EMA, which hosted a joint meeting of the three projects in March 2017. Thereby research results feed into policy making for the development and approval of medicines. The partners are also members of the 'small population clinical trials task force' of IRDiRC.

Under Horizon 2020, a prime example of a PM project is the U-PGx project: 'Ubiquitous pharmacogenomics: making actionable pharmacogenomic data and effective treatment optimization accessible to every European citizen' [41]. The project has been selected following a call for proposals inviting applications on piloting PM in healthcare. The U-PGx project pilots a truly PM approach in a real-life setting. The project conducts pre-emptive genotyping of several pharmacogenes in large patients' cohorts in Austria, Greece, Italy, The Netherlands, Slovenia, Spain and the UK. These prospectively collected data will be linked to the electronic health records (EHR) of patients. A decision support system will be used to analyze the information on prescribed drugs against the patient genotype and phenotype, raising alert in case a potentially risky drug is supposed to be prescribed or dispensed. As the project is implemented in several countries, it will reflect the varied healthcare system organizations in Europe. The U-PGx consortium will also analyze the health outcome and cost-effectiveness of this approach. The project runs for 5 years (2016-2020), funded with $€ 15$ million EU contribution.

\section{IMI PM projects}

The first part of the IMI program is concluded with 59 projects. These projects represent an IMI investment of more than $€ 960$ million, an in-kind contribution from EFPIA companies of a similar amount and a total project cost of $€ 2.2$ billion. Of the projects that have been selected under IMI, 31 address PM. They represent an IMI investment and EFPIA in-kind contribution of some $€ 380$ and 370 million, respectively, and a total investment of more than $€ 870 \mathrm{~m}$. The projects address some of the most prevalent diseases such as cancer, diabetes, Alzheimer's disease or inflammatory diseases, as well as approaches to accelerate drug development.

The IMI PM projects have delivered many important scientific results. For example, the NEWMEDS project ('Novel methods leading to new medications in depression and schizophrenia'; €9 million IMI contribution, $€ 13.8$ million in-kind contribution from EFPIA, €2 million other contributions [42]) has revealed the impact of genetic variants associated with schizophrenia and autism. They still influence cognitive skills and brain structure in people who carry the genes but do not suffer from these conditions.

The IMI PM projects demonstrate the importance and relevance of patient involvement. Under IMI the U-BIOPRED project has been supported: 'Unbiased BIOmarkers in PREDiction of respiratory disease outcomes' (€९.94 million IMI contribution, $€ 14.5$ million EFPIA in-kind contribution, $€ 2.4$ million other contributions) [43]. The project uses information and samples from adults and children to learn more about different types of asthma to ensure better individualized diagnosis and treatment. It is based on samples and medical information from hundreds of adults and children with severe asthma and other respiratory diseases. Six patient organizations have been involved at all stages of the project: as members of the Ethics Board and Safety Monitoring Boards, in the Patient Involvement Platform, and as participants. As one of many outcomes U-BIOPRED has produced a classification for severe asthma into three subtypes, when previous such efforts have failed, providing each asthma patient with improved personalized treatment.

For IMI 2 the initial 15 projects are currently being implemented, with a number of more projects under selection and still a number of calls for proposals to come. Thus, the current set of projects represents only a small part of the total investment that is being made under the program. Out of the projects supported so far, six address PM, focusing on diagnosis including biomarkers and on how to gather data for clinical development in the best manner. The projects receive an IMI2 investment of some $€ 50$ million and an in-kind contribution from EFPIA companies of $€ 45$ million.

The IMI2 project INNODIA 'Translational approaches to disease modifying therapy of Type 1 
diabetes: an innovative approach toward understanding and arresting Type 1 diabetes' [44] ( $€ 17.6$ million IMI contribution, $€ 18.3$ million in-kind contribution from EFPIA and associated partners, $€ 0.6$ million other contributions) aims at a better understanding of Type 1 diabetes, and to lead the way to novel options for preventing and treating the disease. The project recruits a large cohort of newly diagnosed Type 1 diabetes patients and family members of the patients who may also be at risk of developing the disease. Based on this unique resource INNODIA carries out a comprehensive research program to better understand the autoimmune processes that lead to the destruction of the insulin-producing $\beta$ cells. Involvement of patients and their carers is at the heart of the project. They have been strongly involved in the design of the study.

\section{Challenges for EU project funding of PM research}

The European Commission started to invest in PM research when it was very much an emerging area. This meant that early on we faced challenges a research funder is exposed to when investing in a new area, such as how targeted the calls for proposals should be. Broader topics allow the scientific community to present ideas for how to address the area and can lead to investing in projects tackling the diverse challenges. On the other hand such topics do not allow targeting specific needs of a research area and has led to significant over-subscription with many more excellent proposals submitted than we could fund. This unsatisfactory situation may discourage relevant actors from applying to our programs in future.

More targeted topics avoid the mentioned challenges, at the potential risk of not addressing the most relevant research questions. With such topics appropriate consultation of stakeholders needs to occur before and during the preparation of the work programs.

As project funder we also face the challenge that we cannot guarantee sustained support for a given area. Rather, once a promising project comes to an end it needs to compete with all other projects in new calls.

For our investment in PM research we also have to ask to what extent the projects have an impact on policy developments. When developing work programs, together with all involved actors considerable effort is made for the preparation of work programs with clear descriptions of the expected impact of the research to be supported. Nevertheless, based on our experience the expert evaluators sometimes find it difficult to evaluate this aspect. Furthermore, even for projects where according to well established metrics for scientific excellence the projects have been successful, it is much harder to determine the impact on policy and healthcare practice.
Our response to the challenges has been to make a sustained effort of investing in PM research overall and employing a mix of topics, as well as adapting subsequent rounds of calls for proposals based on the learnings from earlier calls.

\section{Outlook for remainder of Horizon 2020}

The work programs for the years 2018-2020 are under preparation. The advice from the Advisory Group to Societal Challenge 1 [45] was delineated into 14 individual sections addressing either topical/vertical or overarching/horizontal and cross-cutting issues and a summary report. One of the individual sections is dedicated to PM. The experts recommend to:

- Build cases for implementation of PM: the program should address better understanding of disease etiologies at the system level (including their co-morbidities and sex-related differences) across a full course of disease development, leading to better diagnostic reclassification, novel biomarkers and targets.

- Focus on specific disease areas for successful implementation of PM: pilot and implement PM in specific cases, building on new disease knowledge and utilizing innovative technologies (e.g., diagnostics, ICT, therapies). Primary focus on disease areas where significant advances in PM approaches have already been made in Europe, for example, rare diseases, oncology, diabetes and its metabolic co-morbidities.

- Wider acceptance of PM and facilitating development of European market for PM: advance governance, semantic interoperability and scalability of EHR across Europe. Focus on supporting development of novel tools for semantic integration of EHRs across different healthcare system (shortterm goal) and harmonization of EHRs across different EU states (long-term goal).

This will address gaps in PM research. The draft AG reports have been put out for a targeted stakeholder consultation in August/September 2016 and the feedback received has been taken up for finalizing the documents [46]. Based on this advice and other input the European Commission has drafted a strategic programming document that is part of the strategic programming process. The thematic report for Societal Challenge 1 has been published together with the other thematic reports, as well as an overarching document [47]. Four priorities have been set for Societal Challenge 1:

- Priority 1: Better health and care, economic growth and sustainable health systems 
Executive summary

EU political context:

Commission as driver for personalized medicine

- The European Commission has been a driver for the development of personalized medicine (PM).

- A 2013 Commission Communication placed the challenges for advancing PM in the context of the medical innovation cycle 'from bench to bedside'.

- In 2011 and 2016 the European Commission has organized two major conferences.

EU legislation

- A number of EU laws have been adopted supporting the development of PM: the clinical trials regulation, the general data protection regulation and the in vitro diagnostics and medical device legislation.

EU Council conclusions on PM

- In December 2015 the European health ministers adopted Council conclusions on PM. Discussions on PM at EU level echo activities at the level of the EU Member States.

International Consortium for Personalized Medicine - IC PerMed

- The EU Member States-led International Consortium for Personalized Medicine, IC PerMed, launched in 2016, aims at establishing Europe as a global leader in PM research, supporting the PM science base through a coordinated approach to research, providing evidence to demonstrate the benefit of PM to citizens and healthcare systems and paving the way for PM approaches for citizens.

EU funding for PM:

FP7 \& Horizon 2020

- In FP7 and Horizon 2020 the European Commission has invested strongly into PM research.

- The programs cover a broad range of research and both contain parts that are specifically targeted toward medical research with $€ 6.1$ and $€ 7.4$ billion allocated, respectively, out of global budgets of 50.5 for FP7 and $€ 77$ billion for Horizon 2020.

Innovative Medicines Initiative

- During FP7 Innovative Medicines Initiative (IMI) was created as a public-private partnership between the European Commission and the European pharmaceutical industry represented by the European Federation of Pharmaceutical Industries and Associations.

- Building on IMI, under Horizon 2020 this initiative has been continued with IMI2.

Support to PM projects under FP7 \& Horizon 2020

- Support for PM research has featured prominently in health research under FP7 and Horizon 2020.

- Out of a total number of 1008 projects funded under the FP7 Health Theme, 209 address PM. In addition, more than half (31) of the $59 \mathrm{IMI}$ projects work on PM.

- For Horizon 2020 after 3 years of the 7-year program, already 163 projects (more than half) address PM, complemented by 6 of the initial 15 IMI2 projects.

Success stories

- Success stories include FP7 projects such as BLUEPRINT, which is part of a global effort on epigenomics research.

- Under Horizon 2020 the U-PGx project pilots a truly PM approach in a real-life setting.

- Under IMI the U-BIOPRED project uses information and samples to learn more about different types of asthma to ensure better individualized diagnosis and treatment.

- Under IMI2 the INNODIA aims at a better understanding of Type 1 diabetes, and to lead the way to novel options for preventing and treating the disease.

Challenges

- Challenges of project funding for PM research have been addressed by making a sustained effort of investing in PM research and employing a mix of topics as well as adapting subsequent rounds of calls for proposals based on the learnings from earlier calls.

Outlook for remainder of Horizon 2020

- For the remainder of Horizon 2020 the support for PM research will continue, addressing identified gaps.

- Consultations with Member States are ongoing, so that the efforts from different funders are coordinated and support IC PerMed.

Future perspective

- Rollout of PM in health systems will lead to changes in the way we approach health and disease.

- For this to happen health and care systems need to embrace the digital transformation.

- Building on information-rich medicine PM will bear fruit through preventing disease and targeting interventions.

- The individual citizen must be at the center. 
- Priority 2: Decoding the role of the overall environment for health and well-being

- Priority 3: Digital transformation in health and care

- Priority 4: Trusted big data solutions and cybersecurity for health and care

$\mathrm{PM}$ is one of the main items under priority 1 but research supporting PM will also be undertaken under the other priorities.

The representatives of Member States to the socalled program committee of Societal Challenge 1 will be involved in the drafting of the work programs. It is to be expected that the work programs will be published in autumn 2017. In this document the topics for 2018 and 2019 will be defined, with some flexibility for the topics for 2020. The work programs 2018 through 2020 will contribute to the implementation of the priorities of IC PerMed [48]. Information about all Horizon 2020 calls for proposals can be found at the Research and Innovation Participant Portal [49].

\section{Conclusion}

Through the research framework programs FP7 and Horizon 2020 the European Commission has invested more than $€ 2.6$ billion in PM projects covering the entire research and innovation value chain for the area. Together with the in-kind contributions from the private partner EFPIA in the IMI and some smaller investments from other partners the total investment made at EU level approaches $€ 3.2$ billion since 2007 until today. Considering the remainder of Horizon 2020, we expect to bring the EU-level investment to more than $€ 4$ billion. This massive investment has mobilized thousands of research teams from across Europe and the world to come up with research results building the basis for PM. First projects piloting PM approaches in healthcare have been launched and we expect that many more results of direct relevance of healthcare practice will be delivered by the European PM research effort.

In view of the challenges ahead, it has become clear that stronger coordination of research investments across Europe is essential. To achieve that, the European Commission has worked with Member States to establish the International Personalized Medicine consortium IC PerMed [24]. The secretariat for this consor-

\section{References}

Papers of special note have been highlighted as:

- of interest; $\bullet$ of considerable interest

1 Pirmohamed M, James S, Meakin S et al. Adverse drug reactions as cause of admission to hospital: prospective analysis of 18,820 patients. BMJ 329(7456), 15-19 (2004). tium has just been established [48]. Within IC PerMed, there will also be opportunities for European health research funders to come together to launch joint calls. For this a so-called European Research Area Network call has been launched with a deadline for submitting applications in April 2017.

The continued investment at EU level and the reinforced collaboration of research and health funders and policy makers bodes well for the development of PM in Europe and beyond.

\section{Future perspective}

We can anticipate that we will see profound changes in the way we approach health and disease, if PM can be rolled out in the health systems. Two aspects will be key for such a transformation to be successful: health and care systems need to fully embrace the digital transformation, which has had profound effects on many industry sectors but has, so far, only had limited impact in health and care systems; building on this 'information-rich medicine', the promise of PM will bear fruit for patients and society at large if it is used primarily for preventing disease and targeting medical interventions where they are most effective. The individual citizen must be at the center of this digitally empowered way of practicing (personalized) medicine.

\section{Acknowledgements}

The authors thank S Milev for helping with the preparation of Figure 2 and $\mathrm{H}$ Collier for careful reading of the manuscript.

\section{Financial \& competing interests disclosure}

The authors have no relevant affiliations or financial involvement with any organization or entity with a financial interest in or financial conflict with the subject matter or materials discussed in the manuscript. This includes employment, consultancies, honoraria, stock ownership or options, expert testimony, grants or patents received or pending, or royalties.

No writing assistance was utilized in the production of this manuscript.

\section{Open access}

This work is licensed under the Attribution-NonCommercialNoDerivatives 4.0 Unported License. To view a copy of this license, visit http://creativecommons.org/licenses/by-nc-nd/4.0/

2 Pedrós C, Formiga F, Corbella X et al. Adverse drug reactions leading to urgent hospital admissions in an elderly population: prevalence and main features. Eur. J. Clin. Pharmacol. 72, 219-226 (2016).

3 Bénard-Laribière A, Miremont-Salamé G, PéraultPochat MC et al. EMIR study group on behalf of the French 
network of pharmacovigilance centres: incidence of hospital admissions due to adverse drug reactions in France: the EMIR study. Fundam. Clin. Pharmacol. 29, 106-111 (2015).

4 Van der Hooft CS, Sturkenboom MC, van Grootheest K et al. Adverse drug reaction-related hospitalisations: a nationwide study in The Netherlands. Drug Safety 29, 161-168 (2006).

5 Wu TY, Jen MH, Bottle A et al. Ten-year trends in hospital admissions for adverse drug reactions in England 19992009. J. R. Soc. Med. 103, 239-250 (2010).

6 Schleidgen S, Klingler C, Bertram T et al. What is personalized medicine: sharpening a vague term based on a systematic literature review. BMC Med. Ethics 21, 14-55 (2012).

7 European Comission. European perspectives in personalised medicine. 12-13 May 2011.

https://ec.europa.eu/research/health/pdf/personalised

8 Commission Staff Working Document. Use of '-omics' technologies in the development of personalised medicine. SWD(2013) 436 final.

http://ec.europa.eu/research/health/pdf/2013-10

9 Regulation (EU) no 536/2014 of the European Parliament and of the council of 16 April 2014 on clinical trials on medicinal products for human use, and repealing Directive 2001/20/EC; OJ L 158/1-76, 27.5.2014

http://ec.europa.eu/health/files/eudralex/vol-1

10 REGULATION (EU) 2016/679 OF THE EUROPEAN PARLIAMENT AND OF THE COUNCIL of 27 April 2016 on the protection of natural persons with regard to the processing of personal data and on the free movement of such data, and repealing Directive 95/46/EC (General Data Protection Regulation); O.J. L 119/1-88, 4.5.2016. http://eur-lex.europa.eu/legal-content/EN/TXT/PDF

11 Council of the European Union. Modernising EU rules for medical devices.

www.consilium.europa.eu/en/policies/new-rules

12 Council of the European Union Personalised medicine for patients - Council conclusions (7 December 2015). http://data.consilium.europa.eu/doc/document/ST-15054

13 Seventh Framework Programme (2007-2013). http://eur-lex.europa.eu/legal-content/EN/TXT/HTML

14 REGULATION (EU) No 1291/2013 OF THE EUROPEAN PARLIAMENT AND OF THE COUNCIL of 11 December 2013 establishing Horizon 2020 - the Framework Programme for Research and Innovation (2014-2020) and repealing Decision No 1982/2006/EC; O.J. L 347/104-173, 20.12.2013.

15 The Innovative Medicines Initiative. www.imi.europa.eu

16 More Information at: www.acmedsci.ac.uk/policy/policy-projects/Stratified

17 Leopoldina Nationale Akademie der Wissenschaften www.leopoldina.org/uploads/tx_leopublication/2014

18 Bundesministerium für Bildung und Forschung. www.gesundheitsforschung-bmbf.de/de/4950.php

19 The 'genomic medicine France 2025' plan, website in French (plan can be downloaded in English from this website). http://aviesan.fr/en/aviesan/accueil/toute-l-actualite/plan
20 Personalized Medicine 2020 and beyond - preparing Europe for leading the global way. www.permed2020.eu/index.php

21 The PerMed Strategic Research and Innovation Agenda. www.permed2020.eu/_media/PerMed_SRIA.pdf

- The PerMed Strategic Research and Innovation Agenda has been the starting point and guidance for the discussions about the research actions to be implemented under International Consortium for Personalised Medicine (IC PerMed).

22 European Commission. Research and Innovation. http://ec.europa.eu/research/index.cfm

23 Personalised Medicine Conference 2016 https://ec.europa.eu/research/conferences/2016

24 Nimmesgern E, Benediktsson I, Norstedt I. Personalised medicine in Europe. Clin. Transl. Sci. doi:10.1111/cts.12446 (2017) (Epub ahead of print).

- Discusses the European efforts to launch the EU Member State-driven initiative IC PerMed.

25 A short description of FP7. http://ec.europa.eu/research/fp7/pdf/fp7-inbrief_en.pdf

26 European Commission. Horizon 2020 - The EU Framework Programme for Research and Innovation.

https://ec.europa.eu/programmes/horizon2020

27 Gal D, Glänzel W, Sipido KR. Mapping cross-border collaboration and communication in cardiovascular research from 1992 to 2012. Eur. Heart J. 38(16), 1249-1258 (2016).

28 Innovative Medicines Initiative. Strategic research agenda. www.imi.europa.eu/content/research-agenda

29 Priority medicines from Europe and the World update. www.who.int/medicines/areas/priority_medicines

30 International Rare Diseases Research Consortium. www.irdirc.org

31 Cardoso F, van't Veer LJ, Bogaerts J et al. 70-gene signature as an aid to treatment decisions in early-stage breast cancer. N. Engl. J. Med. 375(8), 717-729 (2016).

32 Blueprint Epigenomics. www.blueprint-epigenome.eu

33 Bock C, Halbritter F, Carmona FJ et al. Quantitative comparison of DNA methylation assays for biomarker development and clinical applications. Nat. Biotechnol. 34(7), 726-737 (2016).

34 Libertini E, Heath SC, Hamoudi RA et al. Saturation analysis for whole-genome bisulfite sequencing data. Nat. Biotechnol. 34(7), 691-693 (2016).

35 Libertini E, Heath SC, Hamoudi RA et al. Information recovery from low coverage whole-genome bisulfite sequencing. Nat. Commun. 7, 11306 (2016).

36 Rendeiro AF, Schmidl C, Strefford JC et al. Chromatin accessibility maps of chornic lymphocytic leukemia identify subtype-specific epigenome signatures and transrciption regulatory networks. Nat. Commun. 7, 11938 (2016). www.cell.com/consortium/IHEC

- Overview of insights from the International Human Epigenome Consortium. 
Gioma Actively Personalised Vaccine Consortium. http://gapvac.eu

38 Asterix (Advances in Small Trials dEsign for Regulatory Innovation and eXcellence).

www.asterix-fp7.eu

39 IDEAL(Integrated Design and AnaLysis of small population group trials). www.ideal.rwth-aachen.de

40 Inspire(Innovative medhodology for small populations research).

www2.warwick.ac.uk/fac/med/research/hscience/stats

41 Ubiquitous Pharmacogenomics.

http://upgx.eu

42 Newmeds.

www.newmeds-europe.com

43 Unbiased BIOmarkers in PREDiction of respiratory disease outcomes.

www.europeanlung.org/projects-and-research/projects

44 INNODIA.

https://innodia.eu
45 Horizon 2020 Advisory Group for Societal Challenge 1, "Health, Demographic Change and Well-being". https://ec.europa.eu/research/health/pdf/ag_advice

46 European Commission. http://ec.europa.eu/programmes/horizon2020/en

47 Horizon 2020. Work programme. https://ec.europa.eu/programmes/horizon2020/en/what

48 IC Permed International Consortium. www.icpermed.eu

- The website of the IC PerMed secretariat gives access to all information regarding this EU Member State-driven initiative.

49 European Commission Research and Innovation Participant Portal.

http://ec.europa.eu/research/participants/portal/desktop/en

- All calls for proposals under Horizon 2020 are published on this website. Search functions are available. The website also provides links to entities that provide support to applicants. 